\title{
Decreased $\left[{ }^{18} \mathrm{~F}\right]$ Spiperone Binding in Putamen in Idiopathic Focal Dystonia
}

\author{
Joel S. Perlmutter, ${ }^{1,5}$ Mikula K. Stambuk, ${ }^{4}$ Joanne Markham, ${ }^{6}$ Kevin J. Black, ${ }^{1,2,5}$ Lori McGee-Minnich, ${ }^{1}$ \\ Joseph Jankovic, ${ }^{7}$ and Stephen M. Moerlein ${ }^{3,5}$ \\ Departments of ${ }^{1}$ Neurology and Neurological Surgery, ${ }^{2}$ Psychiatry, and ${ }^{3}$ Medicinal Chemistry, ${ }^{4}$ Division of Biology and \\ Biomedical Sciences, ${ }^{5}$ Mallinckrodt Institute of Radiology, and the ${ }^{6}$ Biomedical Computing Laboratory, Washington \\ University School of Medicine, St. Louis, Missouri 63110, and 'Department of Neurology, Baylor College of Medicine, \\ Houston, Texas 77030
}

In this study we have investigated the pathophysiology of two idiopathic focal dystonias: hand cramp with excessive cocontractions of agonist and antagonist hand or forearm muscles during specific tasks, such as writing, and facial dystonia manifested by involuntary eyelid spasms (blepharospasm) and lower facial and jaw spasms (oromandibular dystonia). We used positron emission tomography (PET) to measure the in vivo binding of the dopaminergic radioligand $\left[{ }^{18} \mathrm{~F}\right]$ spiperone in putamen in 21 patients with these two focal dystonias and compared the findings with those from 13 normals. We measured regional cerebral blood flow and blood volume in each subject as well as the radiolabeled metabolites of $\left[{ }^{18} \mathrm{~F}\right]$ spiperone in arterial blood. A stereotactic method of localization, independent of the appearance of the images, was used to identify the putamen in all of the PET images. We analyzed the PET and arterial blood data with a validated nonsteady-state tracer kinetic model representing the in vivo behavior of the radioligand. An index of binding called the combined forward rate constant was decreased by $29 \%$ in dystonics, as compared with normals $(p<0.05)$. There were no significant differences between dystonics and normals in regional blood flow, blood volume, nonspecific binding, permeability-surface area product of $\left[{ }^{18} \mathrm{~F}\right]$ spiperone or the dissociation rate constant. These findings are consistent with a decrease of dopamine $D_{2}$-like binding in putamen and are the first demonstration of a receptor abnormality in idiopathic dystonia. These results have important implications for the pathophysiology of dystonia as well as for function of the basal ganglia.

Key words: dystonia; PET; spiperone; $D_{2}$-like receptors; putamen; blepharospasm; hand cramp
Dystonia is a syndrome of repetitive or sustained involuntary muscle contractions that frequently produce twisting, repetitive movements and abnormal postures (Fahn, 1988). Idiopathic dystonias are distinguished from secondary dystonias (such as those caused by birth injury, stroke, or drug reaction) by the lack of identifiable etiology (Calne and Lang, 1988) and can be classified by affected body part. Generalized idiopathic dystonia often begins in childhood, whereas focal dystonias more frequently start in adult life (Marsden and Harrison, 1974; Fahn, 1988; Greene et al., 1995). There are several types of idiopathic focal dystonia, including blepharospasm and hand cramp. Blepharospasm refers to spasms of involuntary eyelid closure that can be sufficiently severe to render a person functionally blind. Some patients also may have lower facial dystonic spasms; the combination is called cranial dystonia. Dystonic hand cramp is produced by excessive cocontractions of agonist and antagonist hand or forearm muscles during specific tasks, such as writing (writer's cramp) or typing

\footnotetext{
Received June 17, 1996; revised Oct. 15, 1996; accepted Nov. 5, 1996.

This work was supported by National Institutes of Health Grants NS31001, NS32318, and AA-07466 as well as by the Benign Essential Blepharospasm Foundation, the Greater St. Louis Chapter of the American Parkinson's Disease Association, the Clinical Hypotheses Research Section of the Charles A. Dana Foundation, the McDonnell Center for the Study of Higher Brain Function, the generosity of Mr and Mrs. Jefferson Miller, and the Barbara and Sam Murphy Fund. We appreciate useful discussions with Dr. Jonathan Mink and the expert technical assistance of the members of the Division of Radiological Sciences. We also thank Dr. William Hart for referral of some patients who participated in this study.

Correspondence should be addressed to Dr. Joel S. Perlmutter, Division of Radiological Sciences, Washington University School of Medicine, Campus Box 8225, 4525 Scott Avenue, St. Louis, MO 63110.

Copyright (C) 1997 Society for Neuroscience $0270-6474 / 97 / 170843-08 \$ 05.00 / 0$
}

(typist's cramp) (Sheehy and Marsden, 1982; Cohen and Hallett, 1988). Clinically, one might suspect that the idiopathic focal dystonias share a common pathophysiology, because there is frequent overlap of symptoms in individual patients (Jankovic et al., 1991), but the exact etiological relationship among the idiopathic focal dystonias remains unclear (Micheli et al., 1994) despite recent advances in genetics (Ozelius et al., 1989, 1992; Waddy et al., 1991; Bressman et al., 1994; Kramer et al., 1994; Greene et al., 1995).

Numerous reports have described structural abnormalities in basal ganglia contralateral to the symptomatic side in hemidystonic patients (Grimes et al., 1982; Demierre and Rondot, 1983; Pettigrew and Jankovic, 1985). Computed tomography (CT) and magnetic resonance imaging (MRI) have revealed putamenal lesions in patients with secondary dystonias (Marsden et al., 1985; Fross et al., 1987; Obeso and Gimenez-Roldan, 1988; Rutledge et al., 1988; Krauss et al., 1992; Bhatia and Marsden, 1994; Lee and Rinne, 1994), and we found an abnormality of blood flow and oxygen metabolism in the putamen contralateral to the side of the body affected by a post-traumatic paroxysmal hemidystonia despite completely normal brain MRI, CT, and angiogram (Perlmutter and Raichle, 1984). Furthermore, high field-strength MRI demonstrated prolonged $T_{2}$ times in the lentiform nucleus in idiopathic torticollis (Schneider et al., 1994). Overall, these studies suggest that the putamen is a likely site of pathophysiology in dystonia.

Several lines of evidence suggest that abnormalities of dopaminergic pathways also play a key role in the underlying pathophys- 
iology of dystonia (Garver et al., 1976; Ashizawa et al., 1980; Kolbe et al., 1981; Rupniak et al., 1986; Poewe et al., 1988; Perlmutter et al., 1993; Playford et al., 1993; Nygaard, 1995), but the specific nature of the abnormality remains unclear. We have designed this study to investigate whether there is an abnormality of $\mathrm{D}_{2}$-like dopaminergic specific binding sites in putamen in patients with idiopathic focal dystonia. We have limited our study to include only those with hand cramp and facial dystonia, because patients with these conditions can lie within the positron emission tomography (PET) scanner for the required time without sedation, substantial movement, or discomfort.

\section{MATERIALS AND METHODS}

Subjects. We studied 21 patients with dystonia (16 women, mean age = $59 \pm 14$ years, range 25-79), including 14 with cranial dystonia and 7 with dystonic hand cramp, as well as 12 normals ( 6 women, mean age $=53 \pm$ 19, range 21-76) recruited from the Movement Disorders and Neuroophthamology clinics at Washington University, the Movement Disorders Clinic at the Baylor College of Medicine, and referrals from the Benign Essential Blepharospasms and the Dystonia Medical Research Foundation. The patients did not have dystonia in other parts of the body. None of the patients or normals had other neurological or psychiatric disease. All had a Mini Mental State Examination score $>26$ (Folstein et al., 1975) and a Hamilton Rating Scale for Depression score $<6$ (Hamilton, 1960). No subjects were taking medications known to affect dopamine receptor binding. Some of the patients had been treated with botulinum toxin A injections directly into affected muscles, as described in Table 1. Additional details of the subjects are included in Table 1. Patients with dystonia and normals were studied concurrently. These studies were approved by the Human Studies Committee of Washington University and by the Radioactive Drug Research Committee (US Food and Drug Administration). Each subject provided written informed consent before participation.

MRI. Each subject had an MRI of the brain with the Siemens Vision 1.5 $\mathrm{T}$ Magnetom scanner. The following pulse sequences were used: MPRAGE $(T R=9.7 \mathrm{msec}, T E=4 \mathrm{msec}$, flip angle $=12$, time $=6: 36$, pixel size $=1 \times 1 \times 1.25 \mathrm{~mm})$, turbo spin echo $(T R=4100 \mathrm{msec}, T E=$ $110 \mathrm{msec}$, flip angle $=140$, time $=5: 48$, pixel size $=1.19 \times 1 \times 1.25 \mathrm{~mm}$, and proton density $(T R=3675 \mathrm{msec}, T E=20,90 \mathrm{msec}$, flip angle $=90$, time $=8: 54$, pixel size $=1.3 \times 0.90 \times 1.3 \mathrm{~mm})$. A midsagittal scout $T_{1}$-weighted spin echo sequence was used to identify midline structures such as the inner table of the skull and anterior and posterior commissures.

PET. PET studies were done with the Siemens $953 \mathrm{~b}$ in the twodimensional mode with 31 simultaneous slices with $3.4 \mathrm{~mm}$ center-tocenter slice separation (Spinks et al., 1988; Mazoyer et al., 1991). Attenuation factors were measured for each subject by using rotating rod sources of $\left[{ }^{68} \mathrm{Ge}\right] /\left[{ }^{68} \mathrm{Ga}\right]$. Reconstructed transaxial resolution of the emission images was $\sim 12 \mathrm{~mm}$, and axial resolution was $\sim 4.2 \mathrm{~mm}$. Each reconstructed voxel is $\sim 2 \times 2 \times 3.4 \mathrm{~mm}$.

Protocol. All subjects were videotaped on the day of the PET studies. Subjects were placed in the PET scanner, a 20-gauge catheter was inserted into an arm vein for injection of radiopharmaceuticals, and a similar catheter was inserted into a radial artery, after local anesthesia with lidocaine, for sampling arterial blood. The head was positioned to include imaging from the top of the striatum to the lower portions of the cerebellum. We placed ear plugs with radio-opaque markers to confirm that the head was not rotated about the anterior-posterior or vertical axes and then stabilized the head with a polyform plastic mask molded to the subject's head. A lateral skull radiograph taken with a reference PET slice marked by a radio-opaque wire provided a permanent record of the patient's position (Fox et al., 1985). For each emission scan, the eyes were closed and the ears not further occluded. We measured regional cerebral blood volume (rCBV) with a 5 min scan beginning 2 min after inhalation of 50-100 $\mathrm{mCi}$ of $\mathrm{C}^{15} \mathrm{O}$ and regional cerebral blood flow (rCBF) with a $40 \mathrm{sec}$ scan after injection of $50 \mathrm{mCi}^{\circ} \mathrm{H}_{2}{ }^{15} \mathrm{O}$ (Herscovitch et al., 1983; Raichle et al., 1983; Martin et al., 1987; Videen et al., 1987). Radioligand binding was measured with $\left[{ }^{18} \mathrm{~F}\right]$ spiperone $\left(\left[{ }^{18} \mathrm{~F}\right] \mathrm{SP}\right)$, because this was the only dopaminergic radioligand available to us for human studies at the time these studies began. Five milliliters of arterial blood were taken for measurement of the free fraction $\left(f_{1}\right.$; dimensionless) of $\left[{ }^{18} \mathrm{~F}\right] \mathrm{SP}$ in blood (done in duplicate or triplicate) with a centrifree technique (Perlmutter et al., 1986). After adequate time allotted for decay of ${ }^{15} \mathrm{O}$, as much as 5
$\mathrm{mCi}$ of no-carrier-added $\left[{ }^{18} \mathrm{~F}\right] \mathrm{SP}$ containing $<1 \mu \mathrm{g}$ of unlabeled ligand (specific activity $>2000 \mathrm{Ci} / \mathrm{mmol}$ ) was injected intravenously, and PET scans were begun immediately. Initial scans were $60 \mathrm{sec}$ and increased up to $10 \mathrm{~min}$ to maintain adequate counts for statistical accuracy (Perlmutter et al., 1987). During these scans, $\sim 35$ arterial blood samples were collected to measure total radioactivity, and 11 of these samples were assayed in duplicate for the fraction of $\left[{ }^{18} \mathrm{~F}\right]$ activity that represented unmetabolized $\left[{ }^{18} \mathrm{~F}\right] \mathrm{SP}$ (Perlmutter et al., 1986). Subjects were observed continuously throughout the PET procedures. Some of the patients had minimal blepharospasm, but there were no other movements seen.

Data analysis. All volumes of interest (VOIs) were identified by an observer blinded to subject diagnosis. For each subject, we started with the same coordinates for the center of putamen identified on a stereotactic atlas of the brain (Talairach and Tournoux, 1988), then transferred these coordinates to the appropriate single PET slice by a stereotactic method of localization (Fox et al., 1985), and finally expanded the VOI to include putamenal activity on the slices immediately above and below. The same-sized region was outlined on all slices $(9 \times 5$ voxels $)$, and then the regional values were averaged across the three slices and for the right and left putamen. A single hemispheric cerebellar value was averaged from left- and right-sided regions $(5 \times 5$ voxels each $)$ identified on three PET slices. The VOIs were held in a constant position for all frames of the dynamic collection made after injection of $\left[{ }^{18} \mathrm{~F}\right] \mathrm{SP}$ and for the CBV and $\mathrm{CBF}$ images. The $\left[{ }^{18} \mathrm{~F}\right]$ tissue activity curves were decay-corrected to the time of injection of $\left[{ }^{18} \mathrm{~F}\right] \mathrm{SP}$. We calculated radioligand binding with a tracer kinetic model previously described (Perlmutter et al., 1986), validated (Perlmutter et al., 1989, 1991) and applied to human studies (Perlmutter et al., 1987). Briefly, PET and arterial blood data were analyzed with a nonsteady-state two-compartment model to estimate the free fraction of radioligand in the cerebellum ( $f_{2}$; dimensionless) as a measure of the nonspecific binding. This value was assumed to be the same in the putamen, and then a three-compartment, three-parameter nonsteady model was used to estimate the local permeability-surface area product (PS) for $\left[{ }^{18} \mathrm{~F}\right] \mathrm{SP}$ at the blood-brain barrier, the combined forward rate constant (CFRC) of $\left[{ }^{18} \mathrm{~F}\right] \mathrm{SP}$ (this equals the apparent maximum number of specific binding sites times the association rate constant of $\left[{ }^{18} \mathrm{~F}\right] \mathrm{SP}$ for the specific sites) as well as the dissociation rate constant of $\left[{ }^{18} \mathrm{~F}\right] \mathrm{SP}-$ receptor complex. The assumptions and limitations of this approach have been described in detail, including the test-retest variability of calculations of the relevant binding variables (Mintun et al., 1984; Perlmutter et al., 1986, 1987, 1989, 1991).

Statistical analyses. Results were compared between dystonics and normals with unpaired $t$ tests. Because there was only a comparison of mean values from a single VOI value, there was no correction for multiple comparisons.

\section{RESULTS}

No subject had a gross abnormality on MRI scan of the brain. Cerebellar blood flow and blood volume, putamenal blood flow and blood volume, and the measured free fraction of $\left[{ }^{18} \mathrm{~F}\right] \mathrm{SP}$ in blood are listed in Table 2. There were no statistical differences between patients and normals. The typical time course of total radioactivity measured in the arterial blood after injection of $\left[{ }^{18} \mathrm{~F}\right] \mathrm{SP}$ is shown in Figure 1. Most of the area under the curve is within the first few minutes, and it is necessary to sample this part of the curve adequately to permit accurate parameter estimation (Perlmutter et al., 1986). Nearly one-half of the radioactivity in arterial blood by $30 \mathrm{~min}$ after $\left[{ }^{18} \mathrm{~F}\right] \mathrm{SP}$ injection represents radiolabeled metabolites of $\left[{ }^{18} \mathrm{~F}\right] \mathrm{SP}$ rather than $\left[{ }^{18} \mathrm{~F}\right] \mathrm{SP}$ itself, as shown in the inset of Figure 1. An example of the time-dependent measurements of regional radioactivity within the putamen (averaged left and right side) is demonstrated in Figure 2. The parameter estimation method finds the optimal estimates of the unknown variables to make the tracer kinetic model equations fit the observed tissue activity points. The closeness of fit of the model to the data also is shown in Figure 2.

Variables estimated from the tracer kinetic model, including the calculated free fraction of $\left[{ }^{18} \mathrm{~F}\right] \mathrm{SP}$ in brain tissue, the permeability-surface area product (PS) for $\left[{ }^{18} \mathrm{~F}\right] \mathrm{SP}$ in cerebellum, PS for $\left[{ }^{18} \mathrm{~F}\right] \mathrm{SP}$ in striatum, and dissociation rate constant of $\left[{ }^{18} \mathrm{~F}\right] \mathrm{SP}$, are 


\begin{tabular}{|c|c|c|c|c|c|c|}
\hline Patient & $\begin{array}{l}\text { Type of } \\
\text { dystonia }\end{array}$ & Age & Gender & Duration & Medications & $\begin{array}{l}\text { Time of last } \\
\text { oral medicine }\end{array}$ \\
\hline 1 & Cranial & 48 & M & $6 \mathrm{yrs}$ & trihexyphenidyl & $6 \mathrm{hr}$ \\
\hline 2 & Cranial & 54 & $\mathrm{~F}$ & $4.5 \mathrm{yrs}$ & $\begin{array}{l}\text { hydralazine, clonazepam, levothyroxine } \\
\text { btx/2 months ago }\end{array}$ & $6 \mathrm{hr}$ \\
\hline 3 & Cranial & 54 & $\mathrm{~F}$ & $1.5 \mathrm{yrs}$ & $\begin{array}{l}\text { estrogen, progesterone, diclofenac, } \\
\text { indepamide, verapamil } \\
\text { btx } / 2 \text { weeks ago }\end{array}$ & $12 \mathrm{hr}$ \\
\hline 4 & Cranial & 46 & $\mathrm{~F}$ & $4 \mathrm{yrs}$ & $\begin{array}{l}\text { none } \\
\text { btx } / 5 \text { months ago }\end{array}$ & \\
\hline 5 & Cranial & 47 & M & $3 \mathrm{yrs}$ & $\begin{array}{l}\text { aspirin } \\
\text { btx/2 years ago }\end{array}$ & $24 \mathrm{hr}$ \\
\hline 6 & Cranial & 48 & $\mathrm{~F}$ & $3 \mathrm{yrs}$ & $\begin{array}{l}\text { clonazepam, orphenadrine } \\
\text { btx } / 5 \text { weeks ago }\end{array}$ & $24 \mathrm{hr}$ \\
\hline 7 & Cranial & 74 & $\mathrm{~F}$ & $29 \mathrm{yrs}$ & cimetidine & $24 \mathrm{hr}$ \\
\hline 8 & Cranial & 79 & $\mathrm{~F}$ & $16 \mathrm{yrs}$ & $\begin{array}{l}\text { hydrochlorothiazide } \\
\text { btx } / 4 \text { months }\end{array}$ & $24 \mathrm{hr}$ \\
\hline 9 & Cranial & 66 & $\mathrm{~F}$ & $6 \mathrm{yrs}$ & $\begin{array}{l}\text { salicylate } \\
\text { btx } / 5 \text { years ago }\end{array}$ & $24 \mathrm{hr}$ \\
\hline 10 & Cranial & 54 & $\mathrm{~F}$ & $6 \mathrm{yrs}$ & $\begin{array}{l}\text { none } \\
\text { btx } / 6 \text { months ago }\end{array}$ & \\
\hline 11 & Cranial & 54 & $\mathrm{~F}$ & $1 \mathrm{yr}$ & $\begin{array}{l}\text { estrogen } \\
\text { btx/5 weeks ago }\end{array}$ & $24 \mathrm{hr}$ \\
\hline 12 & Cranial & 73 & M & $1 \mathrm{yr}$ & trihexyphenydyl & $24 \mathrm{hr}$ \\
\hline 13 & Cranial & 77 & $\mathrm{~F}$ & $12 \mathrm{yrs}$ & $\begin{array}{l}\text { none } \\
\text { btx } / 4 \text { weeks ago }\end{array}$ & \\
\hline 14 & Cranial & 55 & $\mathrm{~F}$ & $2.5 \mathrm{yrs}$ & $\begin{array}{l}\text { estrogen, levothyroxine } \\
\text { btx } / 4 \text { months ago }\end{array}$ & $24 \mathrm{hr}$ \\
\hline 15 & Hand & 38 & $\mathrm{~F}$ & $10 \mathrm{yrs}$ & none & \\
\hline 16 & Hand & 50 & M & $3 \mathrm{yrs}$ & $\begin{array}{l}\text { none } \\
\text { btx } / 3 \text { months ago }\end{array}$ & \\
\hline 17 & Hand & 59 & $\mathrm{~F}$ & $15 \mathrm{yrs}$ & propoxyphene, atenolol & $24 \mathrm{hr}$ \\
\hline 18 & Hand & 67 & $\mathrm{~F}$ & $9 \mathrm{yrs}$ & $\begin{array}{l}\text { quinapril } \\
\text { btx/1 month ago }\end{array}$ & $24 \mathrm{hr}$ \\
\hline 19 & Hand & 68 & M & $26 \mathrm{yrs}$ & $\begin{array}{l}\text { none } \\
\text { btx } / 3 \text { years ago }\end{array}$ & \\
\hline 20 & Hand & 25 & $\mathrm{~F}$ & $4 \mathrm{yrs}$ & none & \\
\hline 21 & Hand & 45 & $\mathrm{~F}$ & $15 \mathrm{yrs}$ & levothyroxine, estrogen, progesterone & $24 \mathrm{hr}$ \\
\hline Mean & & 56 & $5 \mathrm{M}, 16 \mathrm{~F}$ & 8.5 & & \\
\hline SD & & 14 & & 7.9 & & \\
\hline Range & & $25-79$ & & $1-29$ & & \\
\hline
\end{tabular}

Normals

$\begin{array}{llll}22 & 21 & \text { M } & \text { none } \\ 23 & 53 & \mathrm{~F} & \text { nicotine patch } \\ 24 & 76 & \mathrm{M} & \text { hydrochlorothiazide, lovastatin, aspirin } \\ 25 & 24 & \mathrm{~F} & \text { none } \\ 26 & 40 & \mathrm{M} & \text { none } \\ 27 & 24 & \mathrm{~F} & \text { estrogen, progesterone } \\ 28 & 67 & \mathrm{~F} & \text { gemfibrozil } \\ 29 & 60 & \mathrm{~F} & \text { none } \\ 30 & 64 & \mathrm{M} & \text { none } \\ 31 & 72 & \mathrm{M} & \text { none } \\ 32 & 65 & \mathrm{M} & \text { none } \\ 33 & 63 & \mathrm{~F} & \text { aspirin } \\ \text { Normals } & & & \\ \text { Mean } & 52 & 6 \mathrm{~F}, 6 \mathrm{M} & \\ \pm \text { SD } & 20 & & \end{array}$




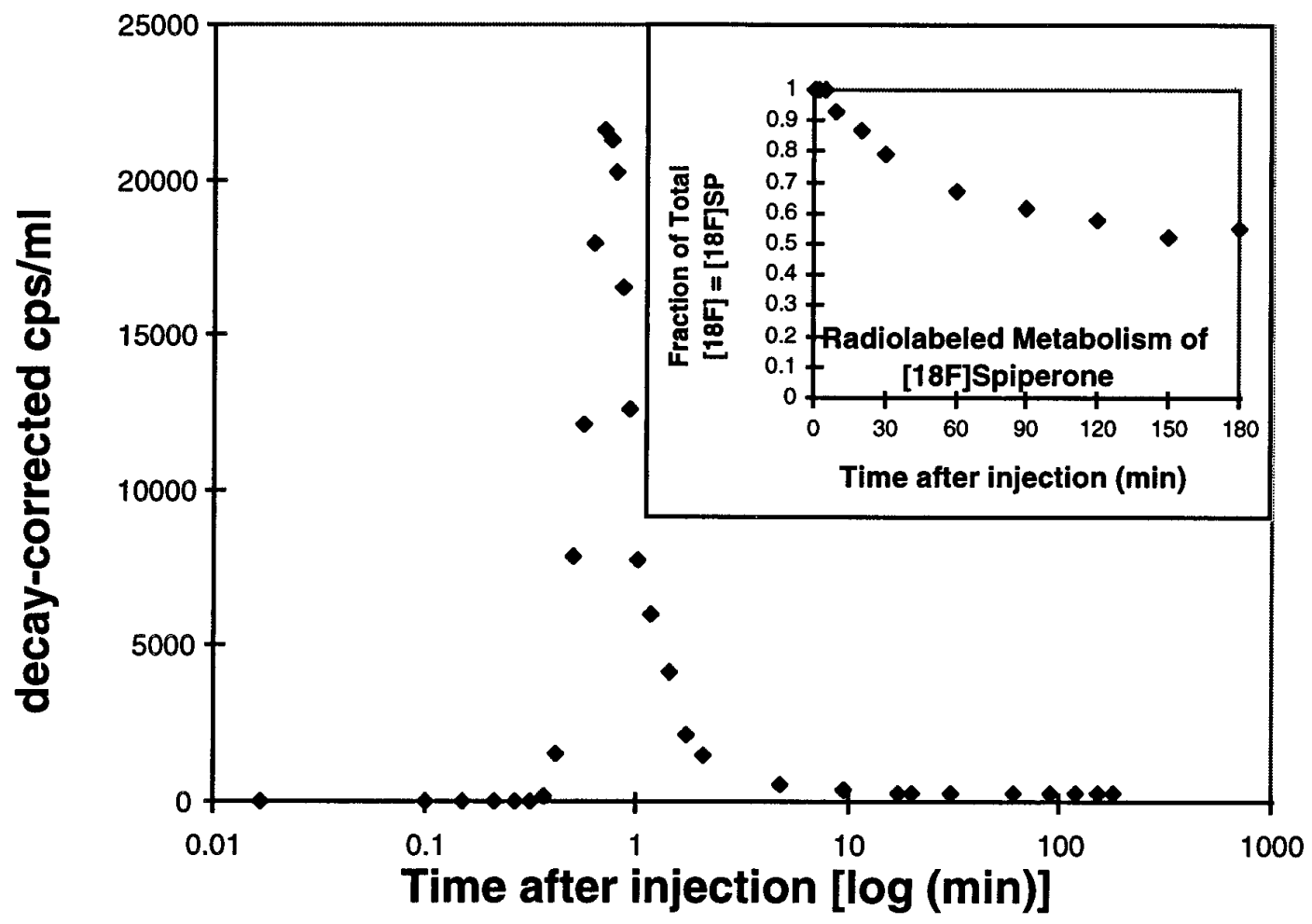

Figure 1. Arterial blood radioactivity after $\left[{ }^{18} \mathrm{~F}\right]$ spiperone injection. This graph represents the measurements made from arterial blood samples in a single subject in this study. Total radioactivity was measured on 31 samples in a well counter cross-calibrated with the PET scanner, and the counts were decay-corrected to the time of radioligand injection. The horizontal axis is shown with a log scale to demonstrate that the majority of the area under the curve occurs in the first few minutes. To delineate this time-activity curve accurately requires frequent sampling at the beginning of the study. The inset graph demonstrates the fraction of radioactivity in blood that represents radiolabeled metabolites, which decreases to $\sim 60 \%$ of the total activity and then remains nearly constant. The radiolabeled metabolites of $\left[{ }^{18} \mathrm{~F}\right] \mathrm{SP}$ were measured as described in Materials and Methods.

Figure 2. Tissue activity curve for putamen. After $\left[{ }^{18} \mathrm{~F}\right] \mathrm{SP}$ injection, 39 sequential PET scans were collected over $3 \mathrm{hr}$. The circles represent regional PET measurements of radioactivity averaged from the left and right putamen over the 3 $\mathrm{hr}$. The measurements were cross-calibrated with the well counter used to measure blood radioactivity and then decaycorrected to time of radioligand injection. The solid curve represents the best fit of the tracer kinetic model equations to the observed tissue activity data. This model represents the behavior of $\left[{ }^{18} \mathrm{~F}\right] \mathrm{SP}$ after injection within the field of view of the PET. The parameter estimation technique determines the optimal values of the unknown variables that yield the best fit of the model to the observed data. Each of the parameter estimations in this study converged to a single optimal solution.

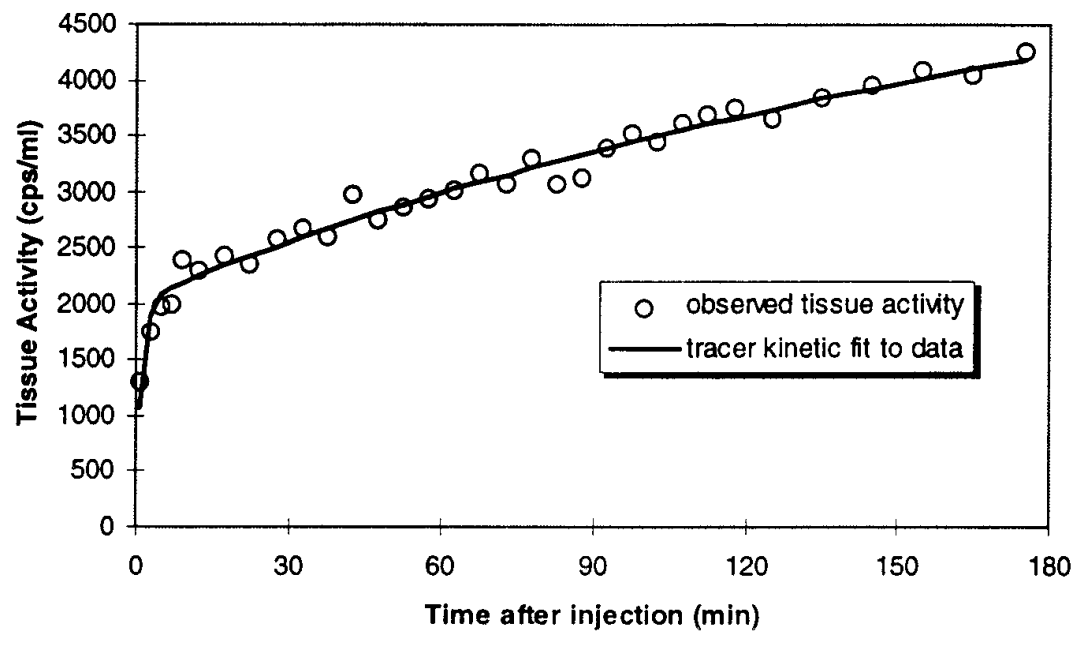

in Table 3. There were no statistically significant differences between dystonics and normals except for the combined forward rate constant, which was $\sim 29 \%$ lower in dystonics compared with normals $(p<0.05)$, as shown in Table 3 . We found no significant difference between the combined forward rate constant for dystonic hand cramp and cranial dystonia $(p>0.2)$. It is important to note that a change in the combined forward rate constant is consistent with a change of the association rate constant, the maximum number of specific binding sites $\left(B_{\max }\right)$, or both. The parameter estimation of the dissociation rate constant has substantially more noise than for the combined forward rate constant.
This is indicated in Table 3 with the greater variance of the estimates of the dissociation rate constant compared with the variance of the estimates of the combined forward rate constant (i.e., higher mean coefficient of variation for the variable estimates). In part, this is attributable to the greater number of association rate events compared with dissociation events that occur during a $3 \mathrm{hr}$ PET study. For this reason, we have chosen to report the combined forward rate constant as the index of binding rather than the binding potential (this equals combined forward rate constant/dissociation rate constant), which would incorporate the additional uncertainty of the dissociation rate constant 


\begin{tabular}{|c|c|c|c|c|c|}
\hline & $\begin{array}{l}\text { Cerebellar CBF } \\
(\mathrm{ml} /[100 \mathrm{gm} \cdot \mathrm{min}])\end{array}$ & $\begin{array}{l}\text { Cerebellar CBV } \\
(\mathrm{ml} / 100 \mathrm{gm})\end{array}$ & $\begin{array}{l}\text { Putaminal CBF } \\
(\mathrm{ml} /[100 \mathrm{gm} \cdot \mathrm{min}])\end{array}$ & $\begin{array}{l}\text { Putaminal CBV } \\
(\mathrm{ml} / 100 \mathrm{gm})\end{array}$ & $\begin{array}{l}\text { Free fraction } \\
\text { in blood }\left(f_{1}\right)\end{array}$ \\
\hline \multicolumn{6}{|l|}{ Dystonics } \\
\hline mean & 71 & 2.8 & 80 & 4.6 & 0.051 \\
\hline $\begin{array}{l} \pm \mathrm{SD} \\
(n=21)\end{array}$ & 15 & 1.0 & 15 & 1.5 & 0.0175 \\
\hline \multicolumn{6}{|l|}{ Normals } \\
\hline mean & 69 & 2.3 & 82 & 4.7 & 0.045 \\
\hline $\begin{array}{l} \pm \mathrm{SD} \\
(n=12)\end{array}$ & 10 & 0.7 & 14 & 1.2 & 0.0070 \\
\hline
\end{tabular}

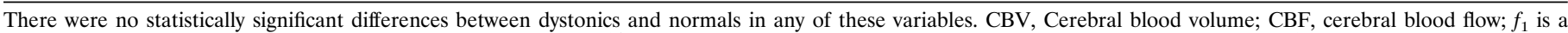

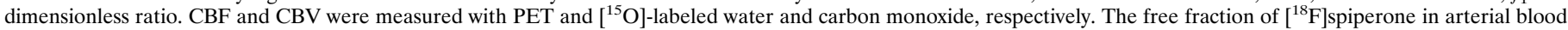
was measured using a microcentrifree technique, as described in Materials and Methods.

estimate (Mintun et al., 1984; Perlmutter et al., 1986). The uncertainty or greater variance of the estimates for the dissociation rate constant limits the detection of statistical differences between groups.

Limitations imposed by potential radiation exposure of subjects and reduced brain penetration of $\left[{ }^{18} \mathrm{~F}\right] \mathrm{SP}$, as compared with other more promising radioligands (Moerlein et al., 1995), reduce the signal-to-noise ratio of PET-based measurements, which tends to increase the variance of the estimated unknown binding variables. To reduce the variance of the estimates, we combined data from the left and right putamen, thus doubling the regional counts to improve signal-to-noise by $\sim 40 \%$. This compromise obfuscates any potential side-to-side differences in a seemingly unilateral condition, such as hand cramp. However, numerous other physiological measurements in hand cramp patients have shown bilateral abnormalities (Panizza et al., 1989, 1990; Tempel and Perlmutter, 1993; Chen et al., 1995; Van Der Kamp et al., 1995), and many patients progress to bilateral hand cramp. Of course, there is no compelling reason to suspect that the patients with bilateral facial dystonia have a unilateral brain abnormality. Thus, we believe that this is a reasonable compromise, given the nature of the data.
Our findings are not likely to be affected by previous treatment of dystonia. Most hand cramp patients had not been treated before the PET, although most blepharospasm patients had previous local injections of botulinum toxin A but were not exposed to oral drugs (Table 1). The direct effects of the toxin probably are limited to the periphery, with blockade of presynaptic release of acetylcholine at the neuromuscular junction (Hamian and Walker, 1994) and minimal penetration of the blood-brain barrier (Black and Dolly, 1987). Although the numbers are small, we did not find a statistical difference in the combined forward rate constant between those patients treated with botulinum versus those not previously treated $(p>0.2)$. The effects of oral medications are not likely to have influenced these findings either. We compared the combined forward rate constant in dystonic patients treated only with botulinum or aspirin $(n=9)$ with normals meeting the same criteria $(n=8)$, and the CFRC was still lower for the dystonics $(0.209 \pm 0.058)$, as compared with the normals $(0.270 \pm 0.142)$.

\section{DISCUSSION}

We found decreased $\left[{ }^{18} \mathrm{~F}\right] \mathrm{SP}$ binding in putamen in patients with facial or hand dystonia, the first demonstration of a receptor

Table 3. PET measurements of $\left[{ }^{18} \mathrm{~F}\right]$ spiperone binding in putamen: variables determined with parameter estimation and the tracer kinetic model

\begin{tabular}{|c|c|c|c|c|c|}
\hline & $\begin{array}{l}\text { Free fraction } \\
\text { in tissue }\left(f_{2}\right)\end{array}$ & $\begin{array}{l}\text { Cerebellar } \\
\text { PS }\left(\sec ^{-1}\right)\end{array}$ & $\begin{array}{l}\text { Putaminal PS } \\
\left(\sec ^{-1}\right)\end{array}$ & $\begin{array}{l}\text { Putaminal } \\
\text { dissociation rate } \\
\text { constant }\left(\mathrm{sec}^{-1}\right) \\
\end{array}$ & $\begin{array}{l}\text { Putaminal combined } \\
\text { forward rate } \\
\text { constant }\left(\mathrm{sec}^{-1}\right)^{*}\end{array}$ \\
\hline \multicolumn{6}{|l|}{ Dystonics } \\
\hline Mean & 0.0053 & 0.038 & 0.051 & 0.00013 & 0.20 \\
\hline$\pm \mathrm{SD}$ & 0.0017 & 0.0139 & 0.016 & 0.00007 & 0.07 \\
\hline Mean COV & $3.3 \%$ & $4.4 \%$ & $3.4 \%$ & $68 \%$ & $29 \%$ \\
\hline $\begin{array}{l} \pm \text { SD COV } \\
(n=21)\end{array}$ & $0.9 \%$ & $1.0 \%$ & $0.9 \%$ & $29 \%$ & $11 \%$ \\
\hline \multicolumn{6}{|l|}{ Normals } \\
\hline Mean & 0.0060 & 0.036 & 0.049 & 0.00017 & 0.28 \\
\hline$\pm \mathrm{SD}$ & 0.0034 & 0.0093 & 0.012 & 0.00011 & 0.14 \\
\hline Mean COV & $3.4 \%$ & $4.5 \%$ & $4.3 \%$ & $80 \%$ & $43 \%$ \\
\hline $\begin{array}{l} \pm \text { SD COV } \\
(n=12)\end{array}$ & $1.1 \%$ & $0.9 \%$ & $1.2 \%$ & $21 \%$ & $24 \%$ \\
\hline
\end{tabular}

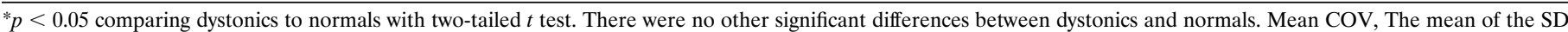

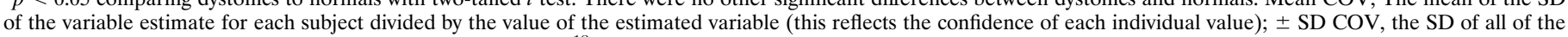

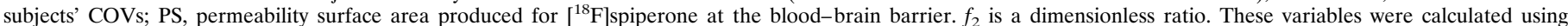

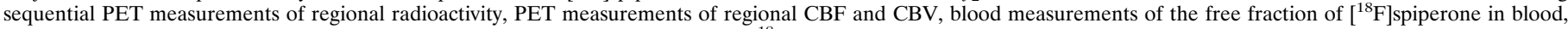

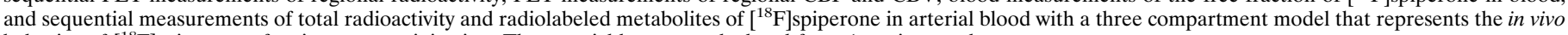
behavior of $\left[{ }^{18} \mathrm{~F}\right]$ spiperone after intervenous injection. These variables were calculated for a $1 \mathrm{cc}$ tissue volume. 
abnormality in idiopathic dystonia. This has important implications for the pathophysiology of dystonia as well as for the function of the basal ganglia.

Our findings must be interpreted cautiously, because $\left[{ }^{18} \mathrm{~F}\right] \mathrm{SP}$ specific binding is relatively nonselective. $\left[{ }^{18} \mathrm{~F}\right] \mathrm{SP}$-specific binding in the nonhuman primate putamen comprises $\sim 74 \%$ to $\mathrm{D}_{2}$-like and $26 \%$ to serotonergic $\mathrm{S}_{2}$ sites (Perlmutter et al., 1991). Furthermore, because $\left[{ }^{18} \mathrm{~F}\right] \mathrm{SP}$ binds to $\mathrm{D}_{2}$-like receptors, $\left[{ }^{18} \mathrm{~F}\right] \mathrm{SP}$ binding could reflect a change in $\mathrm{D}_{2}$ - or $\mathrm{D}_{3}$-specific sites. $\mathrm{D}_{4}$ binding sites are less likely to be relevant, because they are much less numerous in primate putamen (Seeman et al., 1993).

Others have found reduced dopaminergic activity in dystonia consistent with the interpretation that reduced $\left[{ }^{18} \mathrm{~F}\right] \mathrm{SP}$ binding reflects a change in $\mathrm{D}_{2}$-like binding. For example, Playford et al. (1993) found a $15 \%$ mean reduction of $\left[{ }^{18} \mathrm{~F}\right]$ dopa uptake in putamen (and not in caudate) in familial idiopathic dystonia. Others found decreased CSF homovanillic acid (HVA), a major metabolite of CNS dopamine, in one of two patients with cranial dystonia, suggestive of decreased dopamine turnover (Ashizawa et al., 1980), reduced dopamine in GPe (Jankovic et al., 1987) in one patient with cranial dystonia, and reduced striatal dopamine in one of two patients with generalized dystonia (Hornykiewicz et al., 1986). In dopa-responsive dystonia (DRD) there is a remarkable symptomatic response to levodopa. The more common autosomal dominant DRD is associated with a deficiency of an enzyme required for biosynthesis of a cofactor for tyrosine hydroxylase, the rate-limiting enzyme for dopamine production (Nygaard, 1995). The less common autosomal recessive form of DRD is caused by a defect in tyrosine hydroxylase (Knappskog et al., 1995). Furthermore, acute blockade of $\mathrm{D}_{2}$-like receptors with neuroleptics may produce acute dystonic reactions (Garver et al., 1976; Kolbe et al., 1981; Rupniak et al., 1986). Some parkinsonian patients develop dystonia as an early symptom, suggesting that dystonia may result from deficient dopaminergic transmission, because striatal dopamine deficiency produces parkinsonism (Wooten and Trugman, 1989). Similarly, some baboons develop a transient dystonic phase after intracarotid $N$-methyl-4-phenyl1,2,3,6-tetrahydropyridine (MPTP) injection has reduced striatal dopamine levels by $>90 \%$ (Perlmutter et al., 1993). Because most people with Parkinson's disease (PD) do not have dystonia, there must be a difference between the nature of the striatal dopamine deficiency in parkinsonism and dystonia. Parkinsonism is associated with severe striatal dopamine deficiency and presumed secondary dysfunction at both $\mathrm{D}_{1}$-like and $\mathrm{D}_{2}$-like dopamine receptors, whereas we suggest a selective dysfunction of $\mathrm{D}_{2}$-like mediated function in dystonia.

If decreased dopaminergic transmission in putamen produces dystonia, how does this fit with current models of basal ganglia function? One model describes multiple cortical-striato-pallidothalamic-cortical loops with the cortical striate projection fibers of the motor loop predominantly targeting putamen (Alexander et al., 1986; Alexander and Crutcher, 1990; Gerfen et al., 1990; Gerfen, 1992). From there, two major pathways lead to the internal segment of the pallidum (GPi): (1) the direct pathway via inhibitory GABAergic fibers connecting striatum and GPi and (2) the indirect pathway, including inhibitory GABAergic neurons from striatum to the external segment of pallidum (GPe), inhibitory neurons projecting from GPe to subthalamic nucleus (STN), and excitatory neurons projecting from STN to GPi. Both the direct and indirect pathways converge on GPi, which then sends inhibitory GABAergic neurons to ventral anterior thalamus that projects via excitatory neurons to cortical areas, including premo- tor and motor regions. $\mathrm{D}_{2}$-like receptors predominantly localize to and inhibit the striatopallidal neurons of the indirect pathway projecting to GPe, whereas $D_{1}$ receptors localize to and facilitate the neurons of the direct pathway that project from striatum to GPi (Gerfen et al., 1990; Gerfen, 1992; Keefe and Gerfen, 1995). We suggest that dystonia occurs after preferential decrease in $\mathrm{D}_{2}$-mediated inhibition of the indirect pathway. This is consistent with decreased $\left[{ }^{18} \mathrm{~F}\right] \mathrm{SP}$ binding in putamen and with our previous findings of a $25 \%$ reduction in the vibration-induced blood flow responses in primary sensorimotor (PSA) and supplementary motor areas (Tempel and Perlmutter, 1990, 1993). This decreased blood flow response could reflect a primary alteration in cortical activity or alternatively could indicate a change in the corticalstriato-pallidal-thalamic-cortical circuit. A decrease in $\mathrm{D}_{2}$-like inhibitory function would increase the activity of the inhibitory putamen to GPe neurons. This, in turn, would decrease activity of the inhibitory neurons projecting from GPe to STN, leading to increased activity of excitatory neurons projecting from STN to GPi, increased activity of inhibitory neurons projecting from GPi to thalamus, and decreased activity of excitatory neurons projecting from thalamus to cortex. One then might expect that cortical areas would have less activity when interacting with this motor loop through the basal ganglia. Interestingly, we found that a reduced vibration-induced blood flow response in PSA in one patient with a dopa-responsive dystonia (Tempel and Perlmutter, 1990) normalized after levodopa (Perlmutter and Raichle, 1988). We speculate that levodopa modified the PSA response by acting in the putamen, but other sites of action cannot be excluded.

Others have found functional changes in basal ganglia in either animal models or patients with dystonia. Mitchell et al. (1990) measured 2-deoxyglucose uptake in a monkey made hemiparkinsonian after intracarotid MPTP that had developed peak dose dystonia after chronic treatment with the nonselective dopamine agonist apomorphine. They found increased uptake in caudate, putamen, GPe, GPi, and STN but decreased uptake in regions that receive basal ganglia output, such as ventroanterior/ventrolateral thalamus and lateral habenula. These data are consistent with altered activity of dopaminergic pathways in the basal ganglia, but interpretation of the findings is confounded by the activity of the animal during the uptake phase after 2-deoxyglucose injection. Thus, it is unclear whether the findings reflect the underlying pathophysiology of dystonia, the brain responses to altered motor behavior, or both. Stoessl et al. (1986) found in torticollis patients a loss of significant correlations between thalamic metabolism and metabolism in caudate and lentiform nucleus, suggesting a disruption of the pallidothalamic projections. Karbe et al. (1992), also using PET, found an abnormal pattern of regional metabolism, suggesting altered relationships among basal ganglia, thalamus, and frontal association areas in a heterogeneous group of 15 patients with idiopathic dystonia. Although these studies support abnormalities in basal ganglia circuits, they do not identify the specific nature of such dysfunction. Leenders et al. (1993) did not find a significant abnormality in uptake of $\left[{ }^{11} \mathrm{C}\right] N$-methyl-spiperone in six patients mostly with torticollis, although the small number severely hampered identification of a significant result.

One also may view the function of the indirect pathway as broadly inhibiting unwanted movement during an intentional movement and the direct pathway as focally permitting the selected movement (Mink and Thach, 1993). Decreased activity in the indirect pathway could be consistent with normal voluntary initiation of movement but loss of ability to inhibit unwanted 
involuntary movements in other parts of the body. Clinically, this is typical of dystonia, particularly when it first begins. At that time, involuntary postures and muscle spasms may occur only during a specific motor activity and not at rest. The involuntary spasms spread as the movement persists with the loss of "surround inhibition" (Mink and Thach, 1993). This commonly is seen in writer's cramp, because the muscle spasms tend to spread from hand to wrist to arm as writing persists (Sheehy and Marsden, 1982). Under such circumstances, we propose that the "braking action" of the basal ganglia, important for inhibition of excessive movements, has gone awry.

Our findings do not explain all types of dystonia. People with PD may develop dystonia not only as an early manifestation of the disease but also in at least three different patterns associated with dopa replacement therapy. Dystonia may occur commonly in the lower extremities when the plasma dopa levels are low but also may occur when plasma levels peak. Finally, dystonia may occur as the effect of an individual dose begins or as it diminishes (Poewe et al., 1988). Proposing pathophysiological mechanisms for these three patterns of dystonia is difficult, given the uncertainty of the relative influence of the different dopamine receptor subtypes on subsequent activities of the direct and indirect pathways.

In summary, we have found a decrease in $\left[{ }^{18} \mathrm{~F}\right] \mathrm{SP}$ binding in the putamen of patients with idiopathic adult-onset focal dystonias affecting the face or hand. There was no significant difference between patients with hand and facial dystonia, suggesting that there may be a common mechanism producing both conditions, consistent with the clinical impression that they share a similar pathophysiology (Jankovic et al., 1991). However, because we used large VOIs, our data do not exclude the possibility that different areas of putamen may have different degrees of decreased binding in the two types of dystonia. We propose that the pathophysiology of these dystonias reflects decreased activity in the $\mathrm{D}_{2}$-like mediated function of the indirect pathway of the motor circuit in the basal ganglia. Additional studies with more specific radioligands should help to clarify the nature of this abnormality further. It also would be interesting to determine the relative activity of the putamenal neurons projecting directly to GPi versus those projecting to GPe in animal models of dystonia.

\section{REFERENCES}

Alexander G, Crutcher M (1990) Functional architecture of basal ganglia circuits: neural substrates of parallel processing. Trends Neurosci 13:266-271.

Alexander G, DeLong MR, Strick P (1986) Parallel organization of functionally segregated circuits linking basal ganglia and cortex. Annu Rev Neurosci 9:357-381.

Ashizawa T, Patten B, Jankovic J (1980) Meige's syndrome. South Med J 73:863-866.

Bhatia K, Marsden CD (1994) The behavioural and motor consequences of focal lesions of the basal ganglia in man. Brain 117:859-876.

Black JD, Dolly JO (1987) Selective location of acceptors for botulinum neurotoxin $\mathrm{A}$ in the central and peripheral nervous systems. Neuroscience 23:767-779.

Bressman S, Heiman G, Nygaard T, Ozelius L, Hunt A, Brin M, Gordon M, Moskowitz C, de Leon D, Burke R, Fahn S, Risch N, Breakfield X, Kramer P (1994) A study of idiopathic torsion dystonia in a non-Jewish family: evidence for genetic heterogeneity. Neurology 44:283-287.

Calne DB, Lang AE (1988) Secondary dystonia. Adv Neurol 50:9-33.

Chen R-S, Tsai C-H, Chin-Song L (1995) Reciprocal inhibition in writer's cramp. Mov Disord 10:556-561.

Cohen L, Hallett M (1988) Hand cramps: clinical features and electromyographic patterns in a focal dystonia. Neurology 38:1005-1012.

Demierre B, Rondot P (1983) Dystonia caused by putameno-capsulocaudate vascular lesions. J Neurol Neurosurg Psychiatry 46:404-409.

Fahn S (1988) Concept and classification of dystonia. Adv Neurol 50:1-8.
Folstein M, Folstein S, McHugh P (1975) "Mini-mental state": a practical method for grading the cognitive state of patients for the clinician. J Psychiatr Res 12:189-198.

Fox P, Perlmutter J, Raichle M (1985) A stereotactic method of anatomical localization for positron emission tomography. J Comput Assist Tomogr 9:141-153.

Fross R, Martin W, Li D, Stoessl A, Adam M, Ruth T, Pate B, Burton K, Calne D (1987) Lesions of the putamen: their relevance to dystonia. Neurology 37:1125-1129.

Garver DL, Davis DM, Dekirmenjian H, Ericksen S, Gosenfeld L, Haraszti J (1976) Dystonic reactions following neuroleptics: time course and proposed mechanisms. Psychopharmacologia 47:199-201.

Gerfen CR (1992) The neostriatal mosaic: multiple levels of compartmental organization. Trends Neurosci 15:133-139.

Gerfen CR, Engber TM, Mahan LC, Susel Z, Chase TN, Mon Jr FJ, Sibley DR (1990) $D_{1}$ and $D_{2}$ dopamine receptor-regulated gene expression of striatonigral and striatopallidal neurons. Science 250:1429-1432.

Greene P, Kang U, Fahn S (1995) Spread of symptoms in idiopathic torsion dystonia. Mov Disord 10:143-152.

Grimes J, Hassan M, Quarrington A, D’Alton J (1982) Delayed-onset post-hemiplegic dystonia: CT demonstration of basal ganglia pathology. Neurology 32:1033-1035.

Hamian J, Walker F (1994) Serial neurophysiological studies of intramuscular botulinum-A toxin in humans. Muscle Nerve 17:1385-1392.

Hamilton M (1960) A rating scale for depression. J Neurol Neurosurg Psychiatry 23:56-62.

Herscovitch P, Markham J, Raichle M (1983) Brain blood flow measured with intravenous $\mathrm{H}_{2}{ }^{15} \mathrm{O}$ : theory and error analysis. $\mathrm{J} \mathrm{Nucl} \mathrm{Med}$ 24:782-789.

Hornykiewicz O, Kish SJ, Becker LE, Farley I, Shannak K (1986) Brain neurotransmitters in dystonia musculorum deformans. $\mathrm{N}$ Engl J Med 315:347-353.

Jankovic J, Svendeen CN, Bird ED (1987) Brain neurotransmitters in dystonia. N Engl J Med 316:278-279.

Jankovic J, Leder S, Warner D, Schwartz K (1991) Cervical dystonia: clinical findings and associated movement disorders. Neurology 41:1088-1091.

Karbe H, Holthoff V, Rudolf J, Herholz K, Heiss W (1992) Positron emission tomography demonstrates frontal cortex and basal ganglia hypometabolism in dystonia. Neurology 42:1540-1544.

Keefe KA, Gerfen CR (1995) $\mathrm{D}_{1}-\mathrm{D}_{2}$ dopamine receptor synergy in striatum: effects of intrastriatal infusions of dopamine agonists and antagonists on immediate early gene expression. Neuroscience 66:903-913.

Kolbe H, Clow A, Jenner P, Marsden CD (1981) Neuroleptic-induced acute dystonic reactions may be due to enhanced dopamine release on to supersensitive postsynaptic receptors. Neurology 31:434-439.

Knappskog PM, Flatmark T, Mallet J, Ludecke B, Bartholome K (1995) Recessively inherited L-DOPA-responsive dystonia caused by a point mutation $(\mathrm{Q} 381 \mathrm{~K})$ in the tyrosine hydroxylase gene. Hum Mol Genet 4:1209-1212.

Kramer P, Heiman G, Gasser T, Ozelius L, de Leon D, Brin M, Burke R, Hewett J, Hunt A (1994) The DYT1 gene on 9q34 is responsible for most cases of early limb-onset idiopathic torsion dystonia in non-Jews. Am J Hum Genet 55:468-475.

Krauss J, Mohadjer M, Braus D, Wakhloo A, Nobbe F, Mundinger F (1992) Dystonia following head trauma: a report of nine patients and review of the literature. Mov Disord 7:263-272.

Lee M, Rinne J (1994) Dystonia after head trauma. Neurology 44:1374-1378.

Leenders K, Hartvig P, Forsgren L, Holmgren G, Almay B, Eckernas S, Lundqvist H, Langstrom B (1993) Striatal $\left[{ }^{11} \mathrm{C}\right]-N$-methyl-spiperone binding in patients with focal dystonia (torticollis) using positron emission tomography. J Neural Transm 5:79-87.

Marsden C, Harrison M (1974) Idiopathic torsion dystonia (dystonia musculorum deformans) Brain 97:793-810.

Marsden C, Obeso J, Zarranz J, Lang AE (1985) The anatomical basis of symptomatic hemidystonia. Brain 108:463-483.

Martin W, Powers W, Raichle M (1987) Cerebral blood volume measured with inhaled $\mathrm{C}^{15} \mathrm{O}$ and positron emission tomography. J Cereb Blood Flow Metab 7:421-426.

Mazoyer B, Trebossen R, Deutch R, Casey M, Blohm K (1991) Physical characteristics of the ECAT 953B/31: a new high resolution brain positron tomograph. IEEE Trans Med Imag 10:499-504.

Micheli S, Fernandez-Pardal M, Quesada P, Brannan T, Obeso J (1994) 
Variable onset of adult inherited focal dystonia: a problem for genetic studies. Mov Disord 9:64-68.

Mink JW, Thach WT (1993) Basal ganglia intrinsic circuits and their role in behavior. Curr Opin Neurobiol 3:950-957.

Mintun M, Kilbourn M, Welch M, Raichle M (1984) A quantitative model for in vivo assessment of drug binding sites with positron emission tomography. Ann Neurol 15:217-227.

Mitchell I, Luguin R, Boyce S, Clarke C, Robertson R, Sambrook M, Crosn A (1990) Neural mechanisms of dystonia: evidence from a 2-deoxyglucose uptake study in a primate model of dopamine agonistinduced dystonia. Mov Disord 5:49-54.

Moerlein SM, Perlmutter JS, Welch MJ (1995) In vivo receptor binding by a unique PET D-2 radioligand: $N$-methyl- $\left[{ }^{18} \mathrm{~F}\right]$ benperidol. Soc Neurosci Abstr 21:1621.

Nygaard T (1995) Dopa-responsive dystonia. Curr Opin Neurol 8:310-313.

Obeso J, Gimenez-Roldan S (1988) Clinicopathological correlation in symptomatic dystonia. Adv Neurol 50:113-122.

Ozelius L, Kramer P, Moskowitz C, Kwiatkowski D, Brin M, Bresn S, Schuback D, Falk C, Risch N, de Leon D, Burke R, Haines J, Gusella J, Fahn S, Breakfield X (1989) Human gene for torsion dystonia located on chromosome 9q32-34. Neuron 2:1427-1434.

Ozelius L, Kramer P, de Leon D, Risch N, Bresn S, Schuback D, Brin M, Kwiatkowski D (1992) Strong allelic association between the torsion dystonia gene (DYT1) and loci on chromosome 9q34 in Ashkenazi Jews. Am J Hum Genet 50:619-628.

Panizza M, Hallett M, Nilsson J (1989) Reciprocal inhibition in patients with hand cramps. Neurology 39:85-89.

Panizza Lelli S, Nilsson J, Hallett M (1990) H-Reflex recovery curve and reciprocal inhibition of H-reflex in different kinds of dystonia. Neurology 40:824-828.

Perlmutter JS, Raichle ME (1984) Pure hemidystonia with basal ganglion abnormalities on positron emission tomography. Ann Neurol 15:228-233.

Perlmutter JS, Raichle ME (1988) Regional blood flow in dystonia: an exploratory study. In: Advances in neurology, Dystonia 2 (Fahn S, Marsden CD, Calne D, eds). New York: Raven.

Perlmutter J, Larson K, Raichle M, Markham J, Mintun M, Kilbourn M, Welch M (1986) Strategies for the in vivo measurement of receptor binding using positron emission tomography. J Cereb Blood Flow Metab 6:154-169.

Perlmutter J, Kilbourn M, Raichle M, Welch M (1987) MPTP-induced up-regulation of in vivo dopaminergic radioligand-receptor binding in humans. Neurology 37:1575-1579.

Perlmutter J, Kilbourn M, Welch M, Raichle M (1989) Non-steady-state measurement of in vivo receptor binding with positron emission tomography: dose-response analysis. J Neurosci 9:2344-2352.

Perlmutter J, Moerlein S, Huang D-R, Todd R (1991) Non-steady-state measurement of in vivo radioligand binding with positron emission tomography: specificity analysis and comparison with in vitro binding. J Neurosci 11:1381-1389.
Perlmutter JS, Tempel LW, Lich L (1993) A new animal model of dystonia. Soc Neurosci Abstr 19:1052.

Pettigrew L, Jankovic J (1985) Hemidystonia: a report of 22 patients and a review of the literature. J Neurol Neurosurg Psychiatry 48:650-657.

Playford E, Fletcher N, Sawle G, Marsden CD, Brooks D (1993) Striatal $\left[{ }^{18} \mathrm{~F}\right]$ dopa uptake in familial idiopathic dystonia. Brain 116:1191-1199.

Poewe WH, Lees AJ, Stern GM (1988) Dystonia in Parkinson disease: clinical and pharmacological features. Ann Neurol 23:73-78.

Raichle M, Martin W, Herscovitch P, Mintun M, Markham J (1983) Brain blood flow measured with intravenous $\mathrm{H}_{2}{ }^{15} \mathrm{O}$. II. Implementation and validation. J Nucl Med 24:790-798.

Rupniak N, Jenner P, Marsden CD (1986) Acute dystonia induced by neuroleptic drugs. Psychopharmacology (Berl) 88:403-419.

Rutledge J, Hilal S, Silver A, Defendini R, Fahn S (1988) Magnetic resonance imaging of dystonic states. Adv Neurol 50:265-275.

Schneider S, Feifel E, Ott D, Schumacher M, Lucking C, Deuschl G (1994) Prolonged MRI T $T_{2}$ times of the lentiform nucleus in idiopathic spasmodic torticollis. Neurology 44:846-850.

Seeman P, Guan HC, Van Tol H, Niznik H (1993) Low density of dopamine $\mathrm{D}_{4}$ receptors in Parkinson's, schizophrenia, and control brain striata. Synapse 14:247-253.

Sheehy M, Marsden C (1982) Writer's cramp-a focal dystonia. Brain 105:461-480.

Spinks TJ, Jones T, Gilardi MC, Heather JD (1988) Physical performance of the latest generation of commercial positron scanner. IEEE Trans Nucl Sci 35:721-725.

Stoessl A, Martin W, Clark C, Adam M, Ammann W, Beckman J, Bergstrom M, Harrop R, Rogers J, Ruth T (1986) PET studies of cerebral glucose metabolism in idiopathic torticollis. Neurology 36:653-657.

Talairach J, Tournoux P (1988) Co-planar stereotaxic atlas of the human brain. New York: Theime Verlag.

Tempel L, Perlmutter J (1990) Abnormal vibration-induced cerebral blood flow responses in dystonia. Brain 113:691-707.

Tempel LW, Perlmutter JS (1993) Abnormal cortical responses to vibration in patients with writer's cramp. Neurology 43:2252-2257.

Van Der Kamp W, Rothwell J, Thompson P, Day B, Marsden CD (1995) The movement-related cortical potential is abnormal in patients with idiopathic torsion dystonia. Mov Disord 10:630-633.

Videen TO, Perlmutter JS, Herscovitch P, Raichle ME (1987) Brain blood volume, flow, and oxygen utilization measured with O-15 radiotracers and positron emission tomography: revised metabolic computations. J Cereb Blood Flow Metab 7:513-516.

Waddy H, Fletcher N, Harding A, Marsden C (1991) A genetic study of idiopathic focal dystonias. Ann Neurol 29:320-324.

Wooten GF, Trugman JM (1989) The dopamine motor system. Mov Disord 4:S38-S47. 